\title{
Genetic determination in onset age of wrist fracture
}

\author{
Donghai Xiong $\cdot$ Wei Wang $\cdot$ Yuan Chen · \\ Hui Jiang $\cdot$ Hong-Wen Deng
}

Received: 27 November 2006/Accepted: 7 March 2007/Published online: 25 April 2007

(C) The Japan Society of Human Genetics and Springer 2007

\begin{abstract}
The onset age of fracture may be useful to explore the clinical and genetic heterogeneity of fracture study. In the present study, we investigated the heritability of the onset age of wrist fracture (OAWF) in 30 female full-sib pairs. The phenotypic correlation coefficient of OAWF was $0.309(P=0.09)$ for this cohort of female sib pairs, and the narrow-sense heritability $\left(h^{2}\right)$ was estimated to be $0.618(P=0.09)$. In addition, the $h^{2}$ derived from the variance component model implemented in SOLAR was $0.722(P<0.05)$. This study, for the very first time, suggested that OAWF is under genetic control and thus potentially helps clarify genetic heterogeneity of wrist fracture.
\end{abstract}

Keywords Onset age $\cdot$ Wrist fracture $\cdot$ Heritability

D. Xiong · W. Wang · H.-W. Deng

The Key Laboratory of Biomedical Information Engineering of the Ministry of Education and Institute of Molecular Genetics, Xi'an Jiaotong University, Xi'an, Shaanxi 710049,

People's Republic of China

H.-W. Deng $(\square)$

M3-CO3 Medical School, School of Medicine,

University of Missouri-Kansas City, 2411 Holmes Street,

Kansas City, MO 64108, USA

e-mail: dengh@umkc.edu

W. Wang

Osteoporosis Research Center and Department of Biomedical

Sciences, Creighton University, Omaha, NE 68131, USA

Y. Chen $\cdot$ H. Jiang $\cdot$ H.-W. Deng

Laboratory of Molecular and Statistical Genetics, College of Life Sciences, Hunan Normal University,

Changsha, Hunan 410081, People's Republic of China

\section{Introduction}

Wrist fracture (WF) is one of the most common forms of osteoporotic fractures and can help predict subsequent vertebral and hip fractures (Owen et al. 1982; Earnshaw et al. 1998; Cuddihy et al. 1999). The lifetime incidence of WF is generally about $16 \%$ in white women. Previous studies have demonstrated the relatively high heritability of WF, ranging from 25 to 54\% (Deng et al. 2000; Andrew et al. 2005). In addition, it has been shown that family history is a strong predictor for the risk of WF (Keen et al. 1999). To date, linkage studies to identify susceptibility genomic regions underlying fracture per se are rare (Eisman 1999). Although supported by a large sample size, the effect of association between candidate genes and fracture detected in some studies is merely modest, and the results are conflicting in different studies (Nevitt et al. 1991; Nevitt and Cummings 1993; Kiel et al. 1996; Huang et al. 1996; Davee et al. 1990; Bassett and Husted 1997). The difficulties of detection and replication point to the heterogeneity of the condition, including genetic heterogeneity (Eisman 1999) as well as random environmental factors, such as the propensity to fall (Nevitt et al. 1991; Nevitt and Cummings 1993), smoking (Kiel et al. 1996), nutrition (Huang et al. 1996) and physical activity (Davee et al. 1990). To decrease the influence of genetic heterogeneity and thereby facilitate the mapping of susceptibility genes of osteoporotic fracture, it is meaningful to study hidden factors potentially related to the underlying genetic heterogeneity.

Onset age has been proposed as a potential marker of genetic heterogeneity in a variety of complex disorders, including schizophrenia (Bassett and Husted 1997), bipolar disorder (McInnis et al. 1993), Parkinson's disease (Bonifati et al. 1995), breast cancer (Koifman et al. 1998) and 
Alzheimer's disease (Tunstall et al. 2000). For osteoporotic fracture, especially WF, several studies have incorporated onset age as a confounding factor and yielded interesting findings (Andrew et al. 2005; Michaelsson et al. 2005), which encourage additional investigations on the onset age per se. In this study, we aimed to examine whether the onset age of wrist fracture (OAWF) is under genetic control in 30 female full-sib pairs.

\section{Materials and methods}

\section{Subjects and measurement}

The study subjects came from an expanding database being created for studies to search for genes underlying the risk of osteoporosis and obesity in the Osteoporosis Research Center (ORC) of Creighton University. The study was approved by the Creighton University Institutional Review Board and started in 1997. The sample contains a total of 4,498 subjects from 451 pedigrees. All the study subjects were Caucasians of European origin and signed informedconsent documents before entering the project. The general exclusion criterion was elaborated elsewhere (Deng et al. 2002a, b). All subjects were asked to complete a nurseadministered questionnaire to assess the basic information, including the clinical history of WF. The response rate is very close to $100 \%$ since for those who did not complete the questionnaire the first time, we kept sending them the files until they replied. However, the WF information is still missing for those returned questionnaires with the WF column left blank. Subjects with WFs that were not due to low trauma were excluded. Finally, we selected only 30 independent female full-sib pairs with OAWF data since many subjects did not have the required information of OAWF. The mean within-pair differences $( \pm \mathrm{SD})$ in real age and OAWF for our selected 30 female sib-pairs are 5.66 years $( \pm 0.58)$ and 6.49 years $( \pm 0.76)$, respectively. The ranges for the within-pair differences in real age and OAWF are $0-11$ and $0-16$ years, respectively.

\section{Genotyping}

DNA extraction was performed as per our previous protocol (Deng et al. 2002a, b). Three hundred and ninetythree microsatellite markers for the 22 autosomes from the Marshfield screening set 14 were successfully genotyped by the Marshfield Center for Medical Genetics, with the genotyping missing and error rate around $0.3 \%$. The markers have an average population heterozygosity of 0.75 and are spaced on average $8.9 \mathrm{cM}$ apart. The protocol for genotyping is available at http://www.research.marshfieldclinic.org/genetics/LabMethods/-methods.html. PedCheck
(O'Connell and Weeks 1998) was performed to ensure that the genotype data conform to the Mendelian inheritance pattern at all the marker loci. In addition, we used MERLIN (Abecasis et al. 2002) to detect and correct genotyping errors of unlikely recombination (e.g., double recombination) in our sample.

Statistical analyses

Stepwise multiple linear regression analyses were conducted to assess the potential covariates for OAWF, such as height and weight. No significant confounding factors were found. Heritability is defined as the proportion of phenotypic variance attributable to genetic variance. Two specific types of heritability can be estimated. The broad-sense heritability is the ratio of total genetic variance to total phenotypic variance. The narrow-sense heritability is the ratio of additive genetic variance to the total phenotypic variance. In this study, we only analyzed the narrow-sense heritability according to the common practice. We calculated the heritability in two ways. First, we used MINITAB 13.0 (Minitab Inc, State College, PA) to calculate the narrow-sense heritability of OAWF $\left(h^{2}\right)$ according to the following formula (Lynch and Walsh 1997):

$h^{2}=\frac{\sigma_{A}^{2}}{\sigma_{\mathrm{P}}^{2}} \approx \frac{2 \operatorname{Cov}_{\mathrm{fs}}}{\sigma_{\mathrm{P}}^{2}}=2 r_{\mathrm{f} s}$

where $r_{\mathrm{fs}}$ is the phenotypic correlation between full sibs. $\sigma_{A}^{2}$ is the additive genetic variance, and $\sigma_{\mathrm{p}}^{2}$ is the total phenotypic variance. $\operatorname{Cov}_{\mathrm{fs}}$ is the covariance between full-sib pairs. The explanation of the formula (1) is as follows. Full sibs have both parents in common, and the mean genotypic value of a group of full sibs is then equal to the mean breeding value of the two parents, i.e., $0.5\left(A+A^{\prime}\right)$. The additive genetic covariance is therefore the variance of $0.5\left(A+A^{\prime}\right)$., which is $0.25\left(V_{A}+V_{A^{\prime}}\right)=0.5 \sigma_{A}^{2}$ if the additive variance is the same in the two sexes. Assuming that variance due to dominance and the common environment is negligible in full-sib pairs, then the correlation between full sibs is $r_{\mathrm{fs}}=\frac{\operatorname{Cov}_{\mathrm{fs}}}{\sigma_{\mathrm{p}}^{2}}=0.5 \frac{\sigma_{A}^{2}}{\sigma_{\mathrm{P}}^{2}}=0.5 h^{2}$. The significance of $r_{\mathrm{fs}}$ was assessed by the $t$ test (Sokal and Rohlf 1981). Second, we adopted the variance component model implemented in Sequential Oligogenic Linkage Analysis Routines software (SOLAR) (version 2.0.3, available on http://www.sfbr.org/ solar/) to estimate the $h^{2}$ of OAWF. SOLAR uses likelihood ratio tests to evaluate heritability by comparing a purely polygenic model with a sporadic model in the case of testing heritability. Comparison of the likelihood ratio statistic value to the critical value of the chi-squared distribution with the degrees of freedom then gives the significance of the increase in likelihood. Several points need to be pointed out regarding our heritability estimate: First, 
it is specific to the population and environment we are analyzing; second, it is a population rather than individual parameter; finally, the heritability estimate does not indicate the degree to which a trait is genetic; it measures the proportion of the phenotypic variance that is the result of genetic factors.

\section{Results}

The basic characteristics of the 30 female sibling pairs are as follows: the mean age \pm standard deviation (SD) was $66.46 \pm 11.09$ (years); the mean height \pm SD was $159.95 \pm$ $6.62(\mathrm{~cm})$; the mean weight \pm SD was $72.92 \pm 14.75(\mathrm{~kg})$; the mean $\mathrm{OAWF} \pm \mathrm{SD}$ was $57.40 \pm 10.62$ (years).

The correlation coefficient calculated by MINITAB was $0.309(P=0.09)$ for the female sibling pairs, and the $h^{2}$ was thereby 0.618 [ $95 \%$ confidence interval (CI), 0.515, 0.721]. The $h^{2}$ estimate derived from SOLAR was 0.722 (95\% CI, $0.611,0.833)$, and the $h^{2}$ estimate of OAWF by SOLAR tested to be significant $(P<0.05)$.

\section{Discussion}

To the best of our knowledge, this study is the very first that investigates the heritability of OAWF. Heritability estimates using both correlation coefficients and variance component methods converge to suggest the existence of genetic determination of OAWF.

Clinically, the onset age of fracture is useful in mortality rate estimations. For example, the 1st year fracturespecific mortality rate among males/females was $0.15 / 0.03$ for hip fracture occurring before age 75 . The corresponding numbers were $0.24 / 0.12$ for hip fractures occurring at ages $75-84$ and $0.41 / 0.13$ for hip fractures occurring at age 85 or older (Bae et al. 2005). In another study with 33,432 Swedish twins, the authors suggested genetic variation in liability to fracture differed considerably in the onset age. The onset age-adjusted heritability of any osteoporotic fracture was slightly greater than the results unadjusted by onset age (Michaelsson et al. 2005). Incorporation the information of onset age has been proposed as an effective method in linkage study for some complex disorders. Take the linkage analyses for bipolar disorder, for example. Lin et al. (2005) incorporated onset age in linkage analyses and identified two regions of interest. Interestingly, there was little evidence of linkage in their sample until onset age information was included in the analysis. These lines of evidence demonstrated that onset age is likely the maker to demarcate subtypes of the complex disorder with distinct genetic susceptibilities. However, little effort has ever been spent on the onset age of fracture per se. Hence, our genetic study on OAWF represents an initial and important step to close the gap in this field. The detection of genetic determination of OAWF will serve as a starting point to launch numerous studies. Future investigations on fracture could take into account onset age as a covariate or test for linkage/association directly to onset age as a quantitative trait.

There are several issues to be addressed here. First, OAWF data were self-reported. The validity of such information may be degraded by recall bias. However, given WF is symptomatic and almost always requires medical treatment, the investigation of OAWF through questionnaires is still reliable and practical (Ismail et al. 2000). Second, the result obtained by MINITAB was only borderline significant. However, the outcome produced by the variance components method was significant. This inconsistency in significance may be attributable to the small sample size and the different methods to assess significance. Additional investigations with larger sample size are required to replicate and confirm our findings. Finally, since our data consist of only full-sib pairs, our estimation of the heritability may be less accurate compared with the estimations obtained by comparing the correlation coefficient of phenotypes and/or regression coefficient between different sets of pairs including monozygotic pairs, dizygotic pairs, half sibs and those of parents and offspring. In general, $\operatorname{Cov}_{\mathrm{fs}}=0.5 V_{A}+0.25 V_{\mathrm{D}}+V_{\mathrm{EC}}$, where $V_{A}=$ additive genetic variance, $V_{\mathrm{D}}=$ dominant genetic variance and $V_{\mathrm{EC}}=$ shared environmental factors (Falconer and Mackay 1996). However, we do not have data sets to measure $V_{\mathrm{D}}$ and $V_{\mathrm{EC}}$, so we can only assume that the $V_{\mathrm{D}}$ and $V_{\mathrm{EC}}$ components are negligible. Therefore, the $h^{2}$ estimate we reported here is upwardly biased and should be regarded as the upper limit of the heritability of OAWF (Falconer and Mackay 1996). We hope to be able to recruit all types of related pairs for OAWF data in the future and then re-estimate the OAWF heritability for better accuracy.

In conclusion, our study suggested a trend that OAWF is under genetic control and further emphasized that onset age could serve as an important marker for the genetic heterogeneity of fracture.

Acknowledgments HWD was partially supported by grants from NIH (K01 AR02170-01, R01 AR050496-01 and R01 GM6040201A1). The study also benefited from grants from the National Science Foundation of China, the Huo Ying Dong Education Foundation, HuNan Province, Xi'an Jiaotong University and the Ministry of Education of China.

\section{References}

Abecasis GR, Cherny SS, Cookson WO, Cardon LR (2002) Merlinrapid analysis of dense genetic maps using sparse gene flow trees. Nat Genet 30(1):97-101 
Andrew T, Antioniades L, Scurrah KJ, Macgregor AJ, Spector TD (2005) Risk of wrist fracture in women is heritable and is influenced by genes that are largely independent of those influencing BMD. J Bone Miner Res 20(1):67-74

Bae SJ, Paltiel AD, Fuhlbrigge AL, Kuntz KM (2005) Trade-offs between hip fracture mortality and oral corticosteroid usages among white men and women. The 27th annual meeting of the society for medical decision making (21-24 October 2005) Poster Session II: 2005

Bassett AS, Husted J (1997) Anticipation or ascertainment bias in schizophrenia? Penrose's familial mental illness sample. Am J Hum Genet 60(3):630-637

Bonifati V, Fabrizio E, Vanacore N, De Mari M, Meco G (1995) Familial Parkinson's disease: a clinical genetic analysis. Can J Neurol Sci 22(4):272-279

Cuddihy MT, Gabriel SE, Crowson CS, O'Fallon WM, Melton LJ III (1999) Forearm fractures as predictors of subsequent osteoporotic fractures. Osteoporos Int 9(6):469-475

Davee AM, Rosen CJ, Adler RA (1990) Exercise patterns and trabecular bone density in college women. J Bone Miner Res 5(3):245-250

Deng HW, Chen WM, Recker S, Stegman MR, Li JL, Davies KM, Zhou Y, Deng H, Heaney R, Recker RR (2000) Genetic determination of Colles' fracture and differential bone mass in women with and without Colles' fracture. J Bone Miner Res 15(7):1243-1252

Deng HW, Shen -H, Xu FH, Deng HY, Conway T, Zhang HT, Recker RR (2002a) Tests of linkage and/or association of genes for vitamin $\mathrm{D}$ receptor, osteocalcin, and parathyroid hormone with bone mineral density. J Bone Miner Res 17(4):678-686

Deng HW, Deng H, Liu YJ, Liu YZ, Xu FH, Shen H, Conway T, Li JL, Huang QY, Davies KM, Recker RR (2002b) A genomewide linkage scan for quantitative-trait loci for obesity phenotypes. Am J Hum Genet 70(5):1138-1151

Earnshaw SA, Cawte SA, Worley A, Hosking DJ (1998) Colles' fracture of the wrist as an indicator of underlying osteoporosis in postmenopausal women: a prospective study of bone mineral density and bone turnover rate. Osteoporos Int 8(1):53-60

Eisman JA (1999) Genetics of osteoporosis. Endocr Rev 20(6):788-804

Falconer DS, Mackay TFC (1996) Introduction to quantitative genetics. Longman, London

Huang Z, Himes JH, McGovern PG (1996) Nutrition and subsequent hip fracture risk among a national cohort of white women. Am J Epidemiol 144(2):124-134

Ismail AA, O'Neill TW, Cockerill W, Finn JD, Cannata JB, Hoszowski K, Johnell O, Matthis C, Raspe H, Raspe A, Reeve
J, Silman AJ (2000) Validity of self-report of fractures: results from a prospective study in men and women across Europe. EPOS Study Group. European Prospective Osteoporosis Study Group. Osteoporos Int 11(3):248-254

Keen RW, Hart DJ, Arden NK, Doyle DV, Spector TD (1999) Family history of appendicular fracture and risk of osteoporosis: a population-based study. Osteoporos Int 10(2):161-166

Kiel DP, Zhang Y, Hannan MT, Anderson JJ, Baron JA, Felson DT (1996) The effect of smoking at different life stages on bone mineral density in elderly men and women. Osteoporos Int 6(3):240-248

Koifman RJ, Koifman S, Vieira RJ (1998) Familial aggregation of breast/ovarian cancer: age of onset along subsequent generations in Brazil. Cad Saude Publica 14(Suppl 3):181-185

Lin PI, McInnis MG, Potash JB, Willour VL, Mackinnon DF, Miao K, Depaulo JR, Zandi PP (2005) Assessment of the effect of age at onset on linkage to bipolar disorder: evidence on chromosomes 18p and 21q. Am J Hum Genet 77(4):545-555

Lynch M, Walsh B (1997) Genetics and analysis of quantitative traits. Sinauer, Sunderland

McInnis MG, McMahon FJ, Chase GA, Simpson SG, Ross CA, DePaulo JR Jr (1993) Anticipation in bipolar affective disorder. Am J Hum Genet 53(2):385-390

Michaelsson K, Melhus H, Ferm H, Ahlbom A, Pedersen NL (2005) Genetic liability to fractures in the elderly. Arch Intern Med 165(16):1825-1830

Nevitt MC, Cummings SR, Hudes ES (1991) Risk factors for injurious falls: a prospective study. J Gerontol 46(5):M164M170

Nevitt MC, Cummings SR (1993) Type of fall and risk of hip and wrist fractures: the study of osteoporotic fractures. The Study of Osteoporotic Fractures Research Group. J Am Geriatr Soc 41(11):1226-1234

O'Connell JR, Weeks DE (1998) PedCheck: a program for identification of genotype incompatibilities in linkage analysis. Am J Hum Genet 63(1):259-266

Owen RA, Melton LJ III, Ilstrup DM, Johnson KA, Riggs BL (1982) Colles' fracture and subsequent hip fracture risk. Clin Orthop Relat Res Nov-Dec(171):37-43

Sokal RR, Rohlf RJ (1981) Biometry. Freeman, New York

Tunstall N, Owen MJ, Williams J, Rice F, Carty S, Lillystone S, Fraser L, Kehoe P, Neill D, Rudrasingham V, Sham P, Lovestone S (2000) Familial influence on variation in age of onset and behavioural phenotype in Alzheimer's disease. Br J Psychiatr 176:156-159 